\title{
Dialogia
}

\section{Fundamentação teórica na graduação de professores de Educação Física}

\author{
Theoretical foundation in the graduation of Physical Education teachers
}

Dimitri Wuo Pereira

Doutor, Universidade Nove de Julho. Professor, São Paulo, SP, Brasil dimitripereira@uni9.pro.br

Antonio Joaquim Severino

Doutor, Universidade de São Paulo. Professor, São Paulo, SP, Brasil

ajsev@uol.com.br

Resumo: A Filosofia é um campo de conhecimento que estimula a reflexão, a crítica, o debate de ideias e o pensamento racional do ser humano para reconhecer suas atitudes e avaliar seus comportamentos. Na Educação Física brasileira ela ocupa pouco espaço na formação de professores, quer seja pela opinião de que cuida do corpo como uma entidade separada da mente, ou pelo destaque a uma formação mais voltada às Ciências Naturais. Este ensaio pretende colocar alguma luz neste problema analisando as teorias próprias da área que devem fazer parte da formação de professores e que por diversos motivos estão ausentes na graduação. As teorias estão divididas em quatro paradigmas cada qual com um conjunto de ideias. Essa diversidade de opções foi discutida a luz do pensamento complexo de Edgar Morin, apontando o distanciamento entre as correntes filosóficas e as aulas de Educação Física no ensino básico.

Palavras-chave: Formação. Teorias. Educação Física.

\begin{abstract}
Philosophy is a field of knowledge that stimulates the reflection, criticism, discuss of ideas and the rational thought of the human being to recognize their attitudes and evaluate their behaviors. In Brazilian Physical Education, it occupies little space in the formation of teachers, either by the opinion that it takes care of the body as a separate entity from the mind, or by emphasizing a formation more directed to the Natural Sciences. This essay intends to shed some light on this problem by analyzing the theories of the area that should be part of teacher education and that for various reasons are absent in undergraduate studies. Theories are divided into four paradigms each with a set of ideas. This diversity of options was discussed in the light of Edgar Morin's complex thinking checking the distance between philosophical currents and Physical Education classes in elementary education.
\end{abstract}

Key words: Formation. Theory. Physical Education. 


\section{Introdução}

A área de Educação Física se envolve necessariamente com pressupostos filosóficos, seja porque todo campo científico para se constituir e se dar uma identidade específica demanda uma fundamentação epistêmica, seja porque sua eventual aplicabilidade pedagógica precisa sempre lastrear-se em justificativas filosófico-educacionais. Tanto no processo de sua auto-constituição como naquele de autotransformação em conteúdos educativos, a área de Educação Física desenvolve intensa atividade investigativa como tem se esmerado em se consolidar como campo de formação educacional. Em ambas as frentes, tem enfrentado esse desafio de construir fundamentos seguros. Nessa linha, está reverberando e atualizando dilemas próprios da sua construção ao longo da história, que refletem diretamente no modo como se ensinam seus conteúdos na atualidade e em como ela é compreendida pela sociedade.

Tais problemas nascem de diversas situações teóricas e práticas. No cotidiano escolar na forma como os alunos na Educação Básica percebem o dia-a-dia das aulas, muitas delas vistas apenas como brincadeiras ou jogos de futebol, nada parecendo sério, essencial, ou necessário ao futuro profissional. Isto remete a um momento de prazer no ambiente escolar, mas representa a pouca utilidade do conteúdo, sem nenhuma relevância formativa.

Outra situação, igualmente de natureza pedagógica, vincula-se ao local em que as aulas ocorrem: enquanto as disciplinas consideradas importantes são ministradas em salas, espaços considerados nobres pelo senso comum escolar, em que se pode manter a concentração e a ordem, a oferta da Educação Física se espalha na quadra com crianças correndo, gritando e se agitando. Todavia, sabe-se que desde a antiguidade, o corpo é que atrapalharia o aprendizado da mente. O espaço diferenciado criou o problema da necessidade de ambientes amplos para a construção de quadras e isso demanda investimento financeiro, que nem sempre é a disponibilizado no âmbito da gestão escolar, o que expressa a pouca importância que se atribui a esse campo de atividade, não se reconhecendo sua efetiva participação na educação humana. Como elas fundam-se no movimento corporal, necessitam igualmente de materiais diferenciados como bolas, aros, bancos, cordas, raquetes, cones, balanços, etc. Uma gama de equipamentos negligenciados por gestores e por governos que preferem investir em equipamentos tecnológicos, vídeos e computadores considerados mais relevantes por esses agentes e até mesmo pela própria comunidade social envolvente.

Além disso, o próprio efetuar-se da aprendizagem no espaço escolar implica uma concentração no movimentar-se, como se é esperado, mas que ocorre sem consciência clara 
do porquê se faz o movimento. Seria um fazer por fazer, que torna a Educação Física acrítica, pouco reflexiva e descontextualizada com o sentido do aprender, que é compreender o mundo que nos cerca e não se vê seu vínculo com a aprendizagem significativa para os educandos.

O surgimento da Educação Física na escola também remete aos treinamentos militares e a ginástica europeia, tendo uma estrutura edificante na ordem do ambiente escolar e no fortalecimento do corpo para a produtividade. Um redirecionamento equivocado de sua finalidade, que fica então deturpada, questionando-se, por sinal com toda razão, sua presença na escola.

Aliado ao aparecimento com bases guerreiras, ainda houve o entendimento de que o povo brasileiro, na década de 1940/50, carecia da apropriação de hábitos higiênicos, pois no país ocorriam diversas doenças que assolavam a população por falta de limpeza e de cuidados básicos com o corpo (CASTELLANI FILHO, 1988). Numa sociedade ainda agrária e que se encaminhava para o processo de industrialização, a Educação Física foi o veículo que a Medicina encontrou para ajudar no processo de melhoria da saúde;

A formação do professor na Licenciatura carrega todos esses ingredientes e os professores vão entendendo que sua atuação futura será recheada por dificuldades estruturais, políticas, técnicas, econômicas, organizacionais, que, por sua vez, obscurecem os desafios pedagógicos e até mesmo filosóficos, pois os problemas humanos, são efetivamente teóricos e práticos sobre os quais a filosofia se debruça.

\section{As teorias e suas contribuições para a compreensão da área}

Postas estas considerações preliminares, a pretensão deste ensaio é identificar algumas das teorias mais recorrentes, que buscam explicar a natureza da área e propor referências para a formação de seus docentes, refletindo sobre suas repercussões na atuação dos professores da área. Esta pesquisa caracteriza-se como teórico-filosófica, utilizando fontes documentais e bibliográficas. A reflexão apoiou-se em categorias pertinentes ao pensamento complexo de Edgar Morin, para discutir as diferentes propostas e para produzir um entendimento acerca do tema.

O estudo permitiu concluir que, no final do século XX, os PCNs, apresentaram as abordagens desenvolvimentista, construtivista, psicomotora e crítica como alicerces para a atuação dos professores de Educação Física na escola. Elas se estruturam em paradigmas distintos e as contradições existentes entre seus pressupostos causam confusão e necessidade 
de escolha por parte dos professores, quer seja pela decisão de qual ponto de vista políticopedagógico a seguir, quer seja pela dificuldade de compreensão das intencionalidades no seio de cada abordagem.

Estes novos pensamentos na Educação Física escolar enriqueceram o debate sobre a condição da formação na área, que antes se limitava a discutir repetitivamente a aplicabilidade de gestos esportivos ou de exercícios descontextualizados da realidade cultural das crianças, não dialogando com a totalidade do que se propunha no PCN. Os Temas Transversais, por exemplo, exigiam um diálogo transdisciplinar que as referidas abordagens não faziam, pois encerravam-se em si mesmas e não pretendiam abrir-se ao conflito de suas oposições. Escolher uma linha teórica não é suficiente, pois é necessário relacionar seu método de ensino a uma perspectiva de projetos.

A emergência dessa gama variada de constructos teóricos levou a um enriquecimento do debate, porém as discussões geradas no seio da Educação Física alimentaram dúvidas, desequilíbrios e desajustes na compreensão de como dar aula. Se antes existia uma comodidade de propor determinados jogos e atividades, com as abordagens dos PCN's abriu-se o leque de opções para o professor, que nem sempre esteve preparado para entender os conceitos e significados que estavam por trás de cada proposta, tornando-se refém dos discursos provindos da formação na graduação, que neste aspecto sempre foi deficiente, principalmente pela pouca expressão dos conhecimentos filosóficos que deveriam ser trabalhados desde os primeiros anos nos cursos de Licenciatura em Educação Física.

\section{As teorias e suas perspectivas para a Educação Física}

Partindo dessa premissa, apresenta-se agora um sucinto painel com as principais teorias presentes na formação de professores de Educação Física e que aparecem de forma explícita ou implícita em disciplinas de cunho humanístico e pedagógico dos cursos de graduação. A apresentação sintética dessas teorias neste estudo foi estruturada em paradigmas que englobam princípios gerais aos quais elas se vinculam filosoficamente, envolvendo dimensões não só epistêmicas, mas também ontológicas, éticas e políticas.

No âmbito do paradigma biológico situam-se as teorias Desenvolvimentista, a Cinesiologia Humana e a da Atividade Física e Saúde. Essas perspectivas baseiam-se nos preceitos das Ciências Naturais, com ênfase na Medicina. Elas deram impulso primário ao aspecto científico da Educação Física e principiaram as pesquisas empíricas, os estudos com dados estatísticos e o olhar para os cuidados com o corpo da criança, tendo no movimento 
uma possibilidade de desenvolvimento do ser humano para a saúde (TANI, et al. 1988; MARIZ DE OLIVEIRA e RAMOS, 1990; GUEDES e GUEDES, 1993). O ponto de partida destas correntes teóricas é o corpo em movimento, tendo nos aspectos biológicos: fisiologia humana, crescimento humano, anatomia, biomecânica, controle motor, aprendizagem dos movimentos, maturação biológica, saúde, desenvolvimento motor, aptidão física, habilidade motora, as variáveis mais relevantes para a criação de propostas educativas no campo da Educação Física escolar. Nestas propostas, o professor deve estar apto a reconhecer o grupo com quem trabalha, avaliar seus potenciais, desenvolver atividades que estão dentro das capacidades destas crianças e jovens e registrar seu desenvolvimento, apontando aspectos positivos e negativos ocorridos dentro do processo educacional para que se possa melhorar o desempenho futuro e se garantir a saúde através das práticas corporais.

Outro paradigma fundante é o Sócioantropológico, ao qual se vinculam as teorias críticas (Superadora, Emancipatória e Pós-crítica), e as teorias culturais (Cultura Corporal de Movimento e Antropologia Cultural). Numa quase oposição ao estudo centrado na Biologia, este paradigma surgiu na esteira das mudanças sociais pelo qual passou o Brasil, a partir dos anos 1980, período em que uma corrente de pesquisadores com um olhar para as questões sociais, históricas e políticas que determinavam muitas das condições pelas quais os comportamentos humanos ocorriam. Os pensadores dessa linha questionavam a perspectiva naturalista do paradigma biológico, por entenderem que ele não levava na devida conta as condições em que as pessoas viviam e suas interações sociais. Uma das teses defendidas sob esta perspectiva era a da necessidade de a Educação, em geral, e a Educação Física, em particular, serem interventoras e transformadoras da realidade social, não sujeitando o ser humano a sua condição genética e ampliando sua consciência sobre seu papel na sociedade. Essas teorias tecem uma crítica social e revelam a importância da cultura na formação humana. Algumas de suas vertentes recebem influências do marxismo, da Escola de Frankfurt e dos Estudos Culturais de Stuart Hall, e outras têm na Antropologia Cultural sua base de pesquisa (COLETIVO DE AUTORES, 1992; KUNZ, 2001; NEIRA, 2006; CAGIGAL, 1996; DAÓLIO, 1995). As teorias que se organizam neste grupo partem do princípio de que a compreensão da sociedade e do indivíduo inserido nela é essencial para se pensar tanto o indivíduo que se quer formar, quanto a sociedade que se pretende para o futuro. Para os autores as interações sociais são mais importantes do que o desenvolvimento de determinadas capacidades e habilidades individuais, pois os parâmetros de escolha de quais capacidades avaliar depende dos fatores culturais que elegem algumas competências como mais importantes do que outras e isso está diretamente relacionado com quem toma 
as decisões sobre o que deve ser ensinado. Há um deslocamento do professor tradicional como detentor do saber para o mediador do conhecimento. Daí a crítica à burguesia por reduzir, desde a modernidade, o papel da Educação a alcançar fins práticos da produção e do lucro.

A Psicologia influenciou diretamente a forma como se passou a compreender o ser humano e suas relações com o mundo. Freud talvez tenha sido a figura mais eminente a apostar na necessidade de se conhecer o lado obscuro da mente humana com seus estudos sobre o inconsciente. Os trabalhos de Freud ajudaram a florescer na Educação as pesquisas sobre as atitudes e condutas dos estudantes e Reich, um de seus seguidores mais importantes, começa a propor uma aproximação entre o corpo e a mente de forma mais direta, sendo possível verificar que determinados comportamentos se expressam nas posturas corporais (MATTHIESEN, 2001). A corrente Psicomotora, vinculado ao paradigma psicológico, foi desenvolvida por Jean Le Boulch, na França, indo ao encontro das perspectivas integradoras do corpo, da mente e das emoções para criar um método específico de trabalho nas escolas, que envolve o entendimento dos eixos corporais como pontos de desenvolvimento do indivíduo (LE BOULCH, 1987). A Psicomotricidade teve grande influência nos anos 1980/90 na Educação Física brasileira. Ela pretendeu substituir a chamada Educação Física por Educação Psicomotora, pois na Educação Física, segundo essa teoria, ocorre uma separação entre o corpo e a mente: afinal "educa-se o físico". No Brasil, não houve uma renúncia ao termo Educação Física, muito provavelmente pelo apego cultural à terminologia, mas a Psicomotricidade também é compreendida como um método de ensino que engloba os aspectos físicos, sociais, afetivos e cognitivos, assim ela continua sendo usada como base para a ação de professores na escola, entusiasmando-os a irem além da dicotomia corpo e mente, ou biologia e cultura.

Sob o paradigma especificamente filosófico, identificam-se algumas teorias, constituídas a partir das influências francesa e portuguesa, tais como a Praxeologia Motriz, a teoria do Desporto e a teoria da Motricidade Humana. Na Grécia antiga, a razão fora colocada como uma forma de afastar do ser humano a ingerência da mitologia e do sobrenatural nas explicações, até então vigentes, sobre a vida. A partir de então, foi possível criar um império do pensamento lógico sobre os comportamentos humanos, o que nos fez desaguar no Positivismo com sua lógica baseada na técnica, na matemática, na física, na exatidão dos instrumentos, afastando o corpo do saber, ou ainda, tornando o corpo um empecilho ao pleno desenvolvimento das faculdades mentais. E nesse bojo, a educação escolarizada começou a ser estruturada considerando a necessidade de impor regras ao corpo, 
mantendo-o preso para que o pensamento pudesse ocorrer de forma ideal. Somente muito mais tarde, o corpo começa a ser revalorizado e na filosofia se destaca Nietzsche, que volta a perceber a importância do corpo como via para a sabedoria. Estas teorias filosóficas que se desenvolveram no âmbito epistêmico da Educação Física vieram para mostrar o lugar que o corpo tem no desenvolvimento dos potenciais humanos. Um dos aspectos centrais que as diferencia dos demais paradigmas é o fato de se posicionarem como propostas de conhecimento, enquanto as anteriormente apresentadas, colocavam-se prioritariamente como métodos de ensino ou propostas didáticas. Logo de início, depararam-se com a própria inconsistência do termo Educação Física, que a grosso modo é a educação do físico, e carrega um princípio dicotômico por natureza.

A teoria da Praxeologia Motriz é a ciência que estuda as ações ou condutas motoras. Então, nesse caso, o objeto de estudo é a compreensão do movimento humano como ele se apresenta na sociedade. Tem força a compreensão do Esporte como fenômeno mais amplo da cultura corporal (PARLEBÁS, 1997). Interessante observar que, em Portugal, surgiram duas concepções distintas, uma delas provinda do Porto, designada como Teoria do Desporto, afirma que o desempenho corporal nos jogos, lutas, corridas, danças e exercícios expressa nossa existência histórica e finita na Terra e o esporte é uma forma de imortalizar o ser humano que é temporal através da construção de uma cultura que perdura para além do indivíduo (BENTO, 2006). De Lisboa, surgiu a teoria da Motricidade Humana que, baseada na Fenomenologia de Merleau Pounty, recusa a hegemonia do paradigma cartesianonewtoniano e convida a educar os sentidos das pessoas. A Ciência da Motricidade Humana estuda o ser humano em movimento e suas intencionalidades ao movimentar-se, isto é, sua corporeidade (SERGIO, 1996).

O diferencial destas teorias é seu caráter intrinsecamente filosófico, ou seja, não são colonizadas por ciências mães, como a Biologia, a Antropologia, a Ciência Social, a Psicologia, a Física, ou a Medicina. Acreditam seus criadores que para ser reconhecida e respeitada no meio acadêmico e na sociedade, a Educação Física deveria ter o mesmo status de outras Ciências e gozar das mesmas prerrogativas.

\section{As teorias paradigmáticas e seu impacto na Educação Física, no Brasil}

De início, a Educação Física apareceu nas escolas brasileiras apenas como prática de ginástica, seguindo o modelo europeu, creditando a ela um valor de profilaxia e higienização para uma sociedade agrária. Recebeu forte apoio do militarismo, sob cujo modelo se 
formaram os primeiros professores graduados em nível superior no país, o que contribuiu para a consolidação da ideia de ordem ao corpo que ajudasse na criação de um Estado forte. A Educação Física foi então, seduzida pelos ideais do esporte competitivo que prevaleceu no ensino das modalidades como conteúdo central nas escolas. Essa formatação pedagógica da Educação Física não tinha um arcabouço teórico que a fundamentasse e seguia a ordem política e social vigente até os anos de 1980, quando surgiu a pós-graduação na área.

Apesar do grande avanço que significou o crescimento do movimento epistemológico voltado para a consolidação científica na Educação Física ainda existem diversas lacunas, muitas oriundas do pensamento cartesiano, que impregna a maior parte das teorias, do positivismo que relativiza a ciência, da simplificação das matrizes paradigmáticas das quais surgiram as teorias e fundamentalmente da incapacidade de reunir as contradições que perpassam as teorias e que impedem o diálogo aberto e profícuo dos pesquisadores que se resguardam em suas ideias. Parte desse problema, se encontra também no jogo de poder ao qual se sujeitam os atores nas diferentes instâncias das Universidades, afinal "[...] o conhecimento necessita do autoconhecimento" (MORIN, 2002, p. 11).

O pensamento complexo de Edgar Morin nos ajuda a refletir sobre essa problemática, pois ele nos alerta para evitar o determinismo, o erro e a ilusão do conhecimento a que estamos sujeitos. Os paradigmas que encerram as teorias impedem que seus criadores escapem de seus próprios erros, pois em geral, consideram que o conhecimento desenvolvido e embasado cientificamente já está pronto e sem falhas. Devemos estar prontos para a incerteza presente no conhecimento e um paradigma, segundo Morin (2003) circunscreve suas teorias num conjunto fechado de princípios, que impedem ideias opostas de as destruírem. O fechamento defende a teoria de ideias contrárias, mas impede que ela se valide pela possibilidade de ser refutada e de fazer sua autocrítica.

Em relação às teorias biológicas, a confiança exagerada em dados matemáticos e mensurações de eventos físico-químicos costumam não levar em consideração as condições em que os experimentos ocorrem e sua efetiva relação com o dia a dia da escola e dos professores, distanciando-se da realidade do contexto escolar. Isso não significa que seus conhecimentos sejam inválidos, mas sim difíceis de serem interpretados pelo professor e de serem utilizados nas aulas, porque não foram construídos nas condições reais do ambiente escolar. Morin (2003) nos mostra que o conhecimento tem como ponto de partida a natureza mediante a qual a existência se materializa no cosmos, donde evolui para a vida no sentido biológico, mas não se encerra aí e estrutura-se na relação do indivíduo com o meio e com os outros indivíduos formando a sociedade, a cultura e implicando uma ética propriamente 
humana. Ou seja, os conhecimentos presentes nessas teorias nem sempre avançam até os paradigmas sócioantropológicos como se espera de propostas pedagógicas.

Sobre as teorias estruturadas na relação social e humana, é possível fazer um elogio a sua posição de olhar o ambiente escolar como ponto de partida do conhecimento do professor de Educação Física, pois assim elas conseguem manter o foco nas necessidades e nas realidades do professor. Todavia, elas costumam não comportar ideias divergentes, portanto, a ideia de cultura repele a de biologia, a posição política do socialismo não comporta a do liberalismo, o social se sobrepõe ao individual. O princípio dialógico, proposto por Morin (2003), nos informa que é necessário dialogar com as oposições, mas para isso é preciso desprender-se dos dogmas impostos por determinados ideais. A grande dificuldade dessas teorias está na radicalidade da rejeição dos procedimentos, técnicas e métodos provindos das Ciências da Natureza em prol daqueles das Ciências Humanas. Este distanciamento é provocado por um posicionamento político de seus adeptos que veem nas demais teorias valores que seriam contrários à justiça social, igualdade, democracia, diversidade etc., talvez pelo fato das outras teorias se mostrarem apolíticas.

A teoria baseada no paradigma psicológico é bastante abrangente no que se refere à complexidade com que compreende o ser humano. Há nesta teoria, pouca aproximação com o ambiente da Educação Física escolar brasileira por de ter sido proposta por um pesquisador francês. Assim, muitos dos seus princípios são usados pelos professores brasileiros e estudados em muitos cursos de graduação, mas não foram propostos como pedagogias específicas para as escolas básicas do país, pois o contexto, já exposto por Morin (2000) não foi valorizado por quem abordou essa teoria. Mas observa-se que, tal qual expõe Morin (2002) a respeito do domínio do pensamento grego que infiltrou-se nos comportamentos do Império romano mesmo sendo dominado por este, a entrada de pensamentos da corrente psicológica na Educação Física brasileira, mesmo tendo sido sobrepujada pelas propostas hegemônicas nas políticas educacionais brasileiras, inspirou posicionamentos de professores e acabou por influenciar de uma forma ou de outra seus modos de agir.

Por fim, as teorias filosóficas contêm em si a racionalidade como condutora do pensamento e da ação. Isso as aproxima da complexidade moriniana. Ressalta-se que a teoria do Desporto e da Motricidade Humana, apesar de criadas em solo português divergem radicalmente nos seus constructos conceituais distintos e não convergem em suas conclusões sobre os fundamentos da área e de seu ensino. Assim, mesmo a teoria da Motricidade Humana que esteve mais próxima do Brasil pela presença do professor Manuel Sergio na 
UNICAMP, na década de 1990, fica distante do professorado brasileiro pela dificuldade em transpor o campo da teoria para a prática educacional.

A Praxeologia Motriz, por sua vez, não teve repercussão na Educação Física brasileira, pois poucos pesquisadores se debruçaram sobre essas ideias. Sem dúvida isto representou uma falha do campo acadêmico, pois essa teoria contém uma aproximação com a escola e os modos de fazer a educação corporal, valorizando a cultura construída socialmente como ponto de partida para o ensino escolar.

Mesmo com a proximidade das propostas filosóficas ao pensamento complexo, elas ainda carregam alguns problemas. Em primeiro lugar, é preciso retornar à alegoria da caverna de Platão para nos lembrar de que as imagens na caverna podem ser ilusões e que chegar à luz fora da caverna é apenas uma parte da solução do problema, a outra é voltar e ensinar as pessoas, isto é, contar-lhes o que descobriu. As inspirações filosóficas na Educação Física ficam distantes dos cursos de Licenciatura e mesmo quando chegam próximo a eles, não há compreensão dos seus significados.

Outra situação difícil reside na necessidade, já posta por Nietzsche (2001), de que para estar além do bem e do mal, é preciso reconhecer que o não verdadeiro é condição da vida. Teorias, como essas, costumam não admitir sua negatividade, portanto, ficam à mercê da não transformação bioantropossocial para se configurarem como verdade.

\section{Conclusão}

Todas as teorias são fundamentos que deram impulso à Educação Física brasileira e contribuem para a consolidação científica da área. Se ainda não são incorporadas à realidade dos professores, isso se deve ao pouco valor dado nos cursos de formação ao debate das mesmas. Quando apresentadas e discutidas na graduação, isso ocorre de forma direcionada pelo discurso do professor ou pelo valor do currículo, optando por uma delas e deixando de lado o debate da totalidade. Acredita-se que um maior empenho dos cursos de formação no sentido de reconhecer as diversas teorias e de promover discussões a respeito pode melhorar a formação dos futuros professores e torná-los mais aptos na sua ação educacional. Esperase que esse trabalho contribua na construção de novos olhares para a área, evidenciando assim a importância da Filosofia no campo de Educação Física.

\section{Referências}

BENTO, Jorge Olimpio. Corpo e desporto: Reflexões em torno dessa relação. In: 
MOREIRA, Wagner Wey (org.). Século XXI: A era do corpo ativo. Campinas - SP: Papirus, 2006.

CASTELLANI FILHO, Lino. Educaşão Física no Brasil: a história que não se conta. Campinas: Papirus, 1988.

CAGIGAL, José Maria. Obras Selectas. Volumes I, II e III. Comité Olímpico Español e Asociación Española de Deportes para Todos. Madrid: Cádiz, 1996.

COLETIVO DE AUTORES. Metodologia do ensino da educação física. São Paulo: Cortez, 1992.

DAÓLIO, Jocimar. Da cultura do corpo. Campinas: Papirus, 1995.

GUEDES, Dartagnan Pinto; GUEDES, Joana E. R. Pinto. Educação física escolar: uma proposta de promoção da saúde. Revista da Associação dos Professores de Educação Física de Londrina, Londrina - PR, v. 8, n.14, p. 16-23, 1993.

KUNZ, Elenor. Didática da educaşão física 1. 2ª ed. Ijuí - RS: Unijuí, 2001.

LE BOULCH, Jean. Educação psicomotora: psicocinética na idade escolar. Porto Alegre: Artmed, 1987.

MARIZ DE OLIVEIRA, José Guilmar; RAMOS, Silvia C. Coutinho. Relações entre posicionamento filosófico em Educação Física e clima organizacional em escolas de $1^{\circ}$ e $2^{\circ}$ graus. Kinesis, n.6, v.1, 111 - 129, jan./jun. 1990.

MATTHIESEN, Sara Quenzer. Criança, corpo e educação: fragmentos da obra de Wilhelm Reich. Revista Brasileira de Ciências do Esporte, v. 22, n. 2, p. 133-141, jan. 2001.

MORIN, Edgar. Os sete saberes necessários à educação do futuro. $2^{\mathrm{a}}$ ed. Revisão Edgar de A. Carvalho. São Paulo: Cortez, 2000.

MORIN, Edgar. Meus demônios. 3 ed. Rio de Janeiro: Bertrand Brasil, 2002.

MORIN, Edgar. Ciência com consciência. $7^{\mathrm{a}}$ ed. Rio de Janeiro: Bertrand Brasil, 2003.

NEIRA, Marcos Garcia. Educação Física: desenvolvendo competências. 2a ed. São Paulo: Phorte, 2006.

NIETZSCHE, Friedrich Wilhelm. Além do bem e do mal ou prelúdio de uma filosofia do futuro. Curitiba: Hemus, 2001.

PARLEBÁS, Pierre. Problemas teóricos y crisis actual en la Educación Física. Lecturas: EF - Deportes. Revista Digital. Buenos Aires, ano 2, n. 7, out. 1997. Disponível em: http://www.efdeportes.com/efd7/pparl7.htm. Acesso em 02/04/2016.

SÉRGIO, Manuel. Epistemologia da Motricidade Humana. Lisboa: Edições Faculdade de Motricidade Humana, 1996.

TANI, Go.; MANOEL, Edison de Jesus; KOKUBUN, Eduardo; PROENÇA, José Elias. Educaşão Física: fundamentos de uma abordagem desenvolvimentista. São Paulo: Ed. Universidade de São Paulo, 1988. 
Recebido em: 22 set. 2018 / Aprovado em: 25 jun. 2019

\section{$\underline{\text { Cite como }}$}

PEREIRA, Dimitri Wuo; SEVERINO, Antonio Joaquim. Fundamentação teórica na graduação de professores de Educação Física. Dialogia, São Paulo, n. 32, p. 321-332, maio/ago. 2019. Disponível em: https://doi.org/10.5585/Dialogia.n32.10595. 